\title{
Time of day effects on learning and open field activity'
}

$\mathrm{DBA} / \mathrm{lJ}$ and $\mathrm{C} 57 \mathrm{~B} 1 / 6$ male mice learned a maze and open field activity was measured at two different times during the day. Both strains were tested at a high and a low activity period in their daily activity cycle. An interaction between strain and time of testing was found for both measures.

There has been recently an increased interest in daily rhythmicity of physiological functions in animals (Cold Spring Harbor, 1960). This rhythmicity can be an important factor in accounting for different results between laboratories which test Ss at different times of day. The present experiment was undertaken to compare behavioral responses of two mouse strains at different times in their daily activity cycle.

Method

Thirty-eight $\mathrm{DBA} / 1 \mathrm{~J}$ and $37 \mathrm{C} 57 \mathrm{~B} 1 / 6$ male mice were used as Ss: $4 \mathrm{DBA}$ and 3 C57 Ss were used to determine activity rhythms of these strains under a 12:12 light:dark cycle (light from $6 \mathrm{AM}$ to $6 \mathrm{PM}$ ); 10 Ss of each strain learned a maze, five of each strain at a high activity time and five during a low activity period; 24 Ss of each strain were used to measure open field activity, 12 from each strain were tested at each of the aforementioned times.

The activity rhythm measures were taken in an apparatus adapted from Bruell (1962). The box was $12 \times 9 \times 5$ in. and was partitioned into four compartments. Holes in the partitions were positioned such that as $\mathrm{S}$ traversed the box lengthwise it was forced to cross from side to side. A light beam passed through the box to a photocell. As $\mathrm{S}$ moved across the box it interrupted the beam and the photocell activated a counter. Hourly readings were taken of the number of times the beam was interrupted. An $\mathrm{S}$ was placed in the box at $10 \mathrm{AM}$, allowed $2 \mathrm{hr}$. to adapt, and then measures were taken for the next $46 \mathrm{hr}$. Food and water were available ad lib. The activity box was located in the colony room.

Ss were tested on an elevated maze of the Lashley III pattern adapted for use with mice. It was constructed from a $1 \times 14 \mathrm{in.}$ plank turned on edge. The top edge was covered with fine wire screen. Ss were maintained at $80 \%$ ad $\mathrm{lib}$ body weight. Ss were allowed to eat for 1 min. from a food cup at the end of the maze. Ss were placed on the maze with no food available for $5 \mathrm{~min}$. each day for three days before training began. Ss received one trial per day for 14 consecutive days. Number of errors on each trial was recorded. Testing took place between $10 \mathrm{AM}$ and noon and also between $6 \mathrm{PM}$ and $8 \mathrm{PM}$.

Open field activity was measured in a $13 \times 25 \times 25$ in. box lined with oilcloth. The bottom of the box was ruled into 255 -in. squares. Ss were carried from their home cage in a covered round quart cardboard container. The container was inverted, placed in the center of the open field, and then the bottom was removed, leaving the top and the $S$ in the center of the open field. The measure of activity was the number of squares entered during a 5-min. period. Twelve Ss of each strain were measured between $10 \mathrm{AM}$ and noon and 12 were tested between $6 \mathrm{PM}$ and $8 \mathrm{PM}$.

\section{Results}

$\mathrm{DBA} / 1 \mathrm{~J}$ and $\mathrm{C} 57 \mathrm{~B} 1 / 6$ strains showed the same activity cycle. Activity level was low during the lighted half of the cycle. Both strains showed a series of high and low activity periods during the dark half of the cycle. Testing time during the active period of $6 \mathrm{PM}$ and 8 PM was selected because both strains showed maximally reliable high activity at this time. These results indicate that the light cycle of the colony can effectively control the activity cycle of both strains.

An analysis of variance on the total number of errors made by each $\mathrm{S}$ for the 14 days indicated that neither the strain effect nor the time of day effect was significant. The interaction between these two factors was significant $(F=5.05, p<.05)$. Figure 1 shows the nature of this interaction. The DBA Ss made more errors in the high activity period than in the low activity period ( $\overline{\mathrm{X}}$ active $=29.2$; inactive $=13.2$ ); whereas, the C57 Ss made more errors in the low activity period than in the high activity period $(\overline{\mathrm{X}}$ active $=23.4$; inactive $=$ 34.6).

An analysis of variance on the number of squares entered during the $5 \mathrm{~min}$. activity test showed that the strain effect was significant $(F=11.94, p<.01)$, and that the time of testing was not significant. Again, the interaction was significant $(F=8.90, p<.01)$. DBA Ss entered more squares during the low activity period than during the high activity period ( $\bar{X}$ active $=85$; inactive =143); whereas, C57 Ss entered more squares in the high activity period than during the low activity period $(\overline{\mathrm{X}}$ active $=163$; inactive $=149)$. C57 Ss were more active than the DBA Ss in both periods. Figure 1 shows the relationship between time of testing and number of squares entered for both strains.

\section{Discussion}

The results of both parts of this experiment show that the relation between the activity cycle of an animal and its performance on a behavioral task is a very important one. These results have important implications for the comparison between studies of different laboratories because, unless the behavioral 


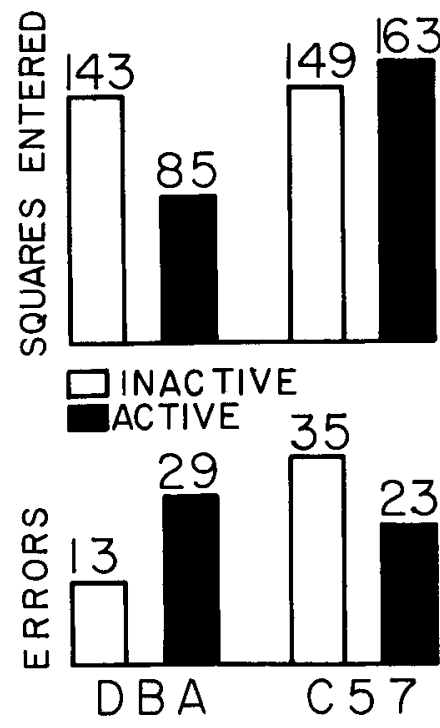

Fig. 1. Mean number of errors and mean number of squares entered for each strain and each time of testing. testing occurs at the same time relative to the lightdark cycle, valid comparison is not possible.

The lack of correlation of the open field test and the cycle of activity as measured in the colony conditions in the DBA strain indicates that the two behavioral tasks are not measuring the same thing. whereas this is not true for the C57 strain.

The fact that many types of animals show cycles with a period of approximately $24 \mathrm{hr}$. is a well established fact (cf. Cold Spring Harbor, 1960). It is apparent from these data that this periodicity is important in at least two types of behavioral tasks and that it can not be ignored when two or more strains are compared on the same behavior or when a single strain is tested on more than one task.

\section{References}

Bruell, J. H. Dominance and segregation in the inheritance of quantitative behavior in mice. In F. L. Bliss (Ed.), Roots of behavior. New York: Hoeber, 1962.

Cold Spring Harbor symposia on quantitative biology: Vol. 25.

Biological clocks. Cold Spring Harbor, N. Y.: LIBA, 1960.

\section{Note}

1. This research was conducted while a USPHS Predoctoral summer fellow at Roscoe B. Jackson Memorial Laboratory, Bar Harbor, Maine. 